\section{CONTRIBUTIONS TO THE DISEASE STATISTICS OF BEDFORD AND ITS NEIGHBOURHOOD.}

By Wilutam Blower, Esq., Bedford.

[Read before the South Midland Branch, September 29th, 1857.]

\author{
I. MEASLES.
}

Measues, according to observations made during my residence at Bedford, occurs as an epidemic in this town every sixth year. Thus it has prevailed here under this form, within the period of my acquaintance with the diseases of this locality, in the years $1826,1832,1838,1844,1850$, and $1850^{3}$; but of its history previous to the earliest of these dates, I have no knowledge. This disease has occasionally been introduced here at other times; but in this case it has not spread extensively, and has only affected those who have had communication with the sick; whereas, in the years specified above, it has prevailed generally throughout the town, and has attacked most of the parties unprotected from it, even in many instances where no direct or indirect exposure to contagion could be traced. It has not always occurred in the same season of the year: in 1826 and 1832 , it prevailed in the winter; in 1838, in the autumn; in 1844, in the spring ; and in 1850 and 1856, in the summer. Its ordinary duration has usually been about four months, exclusive of the occurrence of a few cases before the disease became general and after it had abated. The virulence and the consequent mortality of this disease depend partly upon its type, but principally upon the season of the year at which it occurs : thus, when it has prevailed in the winter and in cold and wet weather, as in 1826 and 1832 , the cases have been severe, and the mortality great; whilst when it has occurred in the summer and in warm and dry weather, the cases have been mild, and the mortality consequently slight.

This periodical recurrence of measles, as an epidemic every sixth year, has not been noticed by any British medical author that I am acquainted with; but Dr. Dewes, an American, mentions it in his treatise on the Diseases of Children.

On two occasions, during my residence at Bedford, a peculiar disease, apparently a compound of measles and scarlet fever, has occurred here as an epidemic. It has the external character of measles and the internal affection of scarlet fever but it is not prevented by previous attacks, nor does it preven future attacks of either of these diseases. Dr. Copland has given a description of it in his Dictionary of Practical Medicine, under the head of "rubeola"; but I am not aware that any other English medical writer has noticed it.

$$
\text { II. BRONCHOCELE. }
$$

Some time ago, I was called to attend a woman at Oakley, who was suffering from a large bronchocele. On inquiring into the history of the case, I learned that it came on during a residence at Ridgemount; and the patient remarked that no female could live in that place for six months without having either a thick neck or thick legs. Shortly afterwards, I was sent by the relieving officer of my district to visit a poor woman residing in Bedford, but who came from Ridgemount; and she too had an enormous bronchocele. I have also been informed by other parties that this disease is very prevalent in that village, and that almost all the inhabitants derived their supply of water, until lately, from one well.

Ridgemount lies about twelve miles south-west of Bedford, on the brow of a hill or chain of hills at the northern extremity of the green sand and near to the Oxford clay. The common well is situated on the side of the hill, near to the top; and the water, on being subjected to chemical analysis, exhibited the absence of free carbonic acid, and consequently of bicarbonate of lime, and also of magnesia. The water of the well at the railway station in the valley contains an abundance of these substances, and no case of bronchocele has ever occurred here. $\mathrm{T}$ : Duke of Bedford has, within the last two or three years, caused other wells to be dug; but I am not acquainted with the contents of their waters, or whether any change has taken place in the prevaleuce of bronchocele, since they have been used.

The absence of free carbonic acid and of bicarbonate of lime from the water in places where bronchocele is endemic, has been recorded by many observers. Thus, Dr. Falk, in his thesis on the Endemic Bronchocele of Nassau and the Elec. torate of Hesse, relates that in the places where this disease is frequent, the water is characterised by the absence of free carbonic acid, and consequently of bicarbonate of lime. Dr. Black, in an article on the Medical Topography of Bolton, inserted in the fifth volume of the Transactions of the Provincial
Medical and Surgical Association, states that bronchocele is so prevalent in that town as to be reckoned an endemic, and that the water contains only an appreciable impregnation of lime. Humboldt also says, that it prevails in districts where the water is free from calcareous impregnations. And many other writers state the same fact either directly or indirectly.

Bronchocele is not of common occurrence in the town and neighbourhood of Bedford, except at Ridgemount, and in persons who have resided there. A slight enlargement of the thyroid gland is occasionally seen in strumous and anæmic young females, but the tumour does not attain the size or acquire the character of genuine bronchocele. The spring water contains free carbonic acid and bicarbonate of lime in considerable quantities; but the river water is nearly destitute of these substances. Persons who live near the river use the water without being subject to bronchocele. This exception, however, can be accounted for by the fact, that the water contains a large quantity of chloride of calcium-a substance which, under the name of muriate of lime, was regarded before the discovery of the medicinal properties of iodine as a potent remedy for bronchocele - and thus, that the simultaneous occurrence of the antidote with the bane prevents its evil consequences.

Numerous theories of the cause of bronchocele have been published, but not one of them has stood the test of criticism. It may, therefore, appear presumptuous to bazard another, which may run the risk of sharing the fate of its predecessors. I trust, however, that I have made out a case which merits further investigation, and one which will induce medical prac. titioners, resident in or near places where bronchocele is endemic, to analyse the water, and ascertain whether it shows the same deficiency of free carbonic acid and bicarbonate of lime, as in the instances narrated above.

\section{NYCTALOPIA.}

Nyctalopia, that morbid affection of the visual organs in which the patients can see in the day-time, but are blind during the night, has generally been considered by ophthalmic authorities to be of rare occurrence in this country. Within the last few years, however, numerous cases have .occurred at Kempston, a large and populous village situated about two miles west of Bedford. It was first noticed about the year 1840 ; and for some time it appeared to be exclusively confined to that place; but latterly a few cases have been observed in the surrounding parishes. The parties affected have been almost exclusively males. I have not heard of more than two females who have suffered from it. All the patients, except one male and the two females, have been employed in the open air from sunrise to sunset; they have principally been agricultural labourers or gardeners, and they have belonged to the poor and labouring classes. It has occurred at all ages, and has attacked boys of 12 years, and old men of 70 . It usually commences at the latter end of February, and continues until June, when it ceases, and does not recur in the autumn. Those persons who have once suffered from it, appear predisposed to be affected again the next spring. Last year, how ever, I met with a case in August, and this year I have met with another in September (the present month); and these two cases, together with that of one of the fermales who was subject to it during pregnancy, have been the only exceptions to its occurrence in the spring. The number of cases seems to be in some measure dependent upon the season; as after mild winters, when there has been but little snow, the cases have been few; whilst after severe winters, when there has been much snow, the cases have been more numerous.

It does not in general prevent the patients from following their accustomed occupations; as the agricultural labourers and gardeners have been able to continue their employment during the day, although they have not unfrequently been obliged to be led home from their places of work in the evening, when they have stayed out after sunset. In the case which occurred in August 1856, the man told me he had to be guided off the corn-stacks which he was building when he remained until dusk; and in the case of the present month, the patient, a carpenter, resident in Bedford, but who has been working at his trade at Kempston for the last six weeks, and who was attacked about a month ago with nyctalopia, has his face marked by contusions which have been occasioned by his inability to see when he has been late in going home. These persons have only experienced inconvenience in the evening and night, and have not suffered any pecuniary loss by the disease; but in one instance, the patient, a game-keeper, whose duty included watching the preserves at night, was incapaci- 
tated for this servica, and, of course, was dismissed from his office.

A few of the patients have complained of aching about the cjebrows; but the greater part sustain no pain or inconvenience, except that arising from the blindness at night. They appear to see tolerably well during the day, but at sunset the sight becomes dim, and as the darkness increases, the dimness of sight increases, until they become totally blind. On a care ful examination, the only deviation from the normal character of the eye observable is a dilatation of the pupil, indicating diminished sensibility of the retina-the probable cause of the blindness in a dim light. The sight docs not sustain any permanent injury; as, after midsummer, in those cases which occur in the spring, it is as good as it was before the attack.

The parties aftected by it do not take so much notice of it now as they did when it first occurred, for they find by experience that it ceases at midsummer, and that medicine has but little influence upon it. The popular remedy is the effluvium from fried bullock's liver, but it appears to have but little if any good effect. Five grains of bluc pill taken at becl-time relieves the brow-ache, and seems-at least, in the opinion of the sufferers-to mitigate the affection, so as to have acquired for the medicine the name of " night-blind pills". Patient endurance, fortified with the confiderice that the affection will cease at midsummer, and the careful avoidance of being from home ufter sunset, is, however, on the whole the best course for the sufferer to pursue.

\section{LABOUR, WITH PERFECT OBLITERATION OF THE OS UTERI.}

By R. G. Mayse, M.D., Surgeon, Leeds. [Continued from page 552.$]$

I sTATED that I had neither heard nor read of a strictly analogous case, and now offer the grounds of this qualified state. ment.

The late Dr. Wm. Campbell of Ellinburgh, in his obstetrical work, relates two cases of very close contraction of the os thus : "Both were first pregnancies: in the first, uterine action continued about twelve hours before the os uteri could be distinguished, when it felt like a minute cicatrix." . . . "The second had regular pains for two nights and a day before the os uteri could be perceived, and she suffered so severely as to require three persons to keep her in bed. Buth patients were largely bled, gave birth to living children, and had a good recovery."

Cburchill had “ $n$ case in which the os uteri was not observable until after forty hours of labour, and then it was felt about the size of a small crowquill. Notwithstanding the delay and obstruction, however, the paticnt was delivered naturally of a living child."

Rigby says: "We may suspect the protraction of labour arises from agglutinated os uteri when at an early period of it we can discorer no restige of the opening in the globular mass formed by the inferior segment of the uterus, which is forced down into the pelvis, or at auy rate when we can only detect a small fold or fossa, or merely a concavity, at the lottom of which is a slight indentation, and which is usually a considerable distance from the median line of the pelvis. The pains come on regularly and powerfully; the lower segment of the uterus is pushed deeper into the eavity of the pelvis, even to its outlet, and becomes so tense as to threaten rupture; at the same time, it becomes so thin that a practitioner who sees such a case for the first time would be induced to suppose the head was presenting, merely covered by the membranes. After a time, by the increasing severity of the pains, the os uteri at length opens, or it becomes necessury that this should be effected by art; when once this is attained, the os uteri goes on to dilate, and the labour proceeds naturally, unless the patient is too much exhausted by the severity of her labour."

Burns (Midwifcry, ed. ix, p. 4(i0) states: "The os uteri may be naturally very small. In some instances, it has with difficulty ailmitted a sewing meerle; and in somo instances I found it impervious, hard, circular, and with difficulty discovered, but it gradually dilated."*

These cases, real and hypothetical, refer to first pregnancies,

- "In a case probably of thls lind, hom Guy's IIospital heports, no os uteri could be felt. An incision w's made into the tuunour formed by tho uterus in the vagina, and the contractions seem to have lacerated this farther. Great exhaustion followed the laceration and birth of he child, with rapid pulse; but the patient recovered." (Lanct, June 103\%, p. 39\%.) and to patent, though extremely constricted os, in one instance indistinguishable till after twelve hours action of the uterus, when it felt "like a minute cicatrix"; in another, imperceptible till after "regular pains for twn nights and a day"; in a third, not discoverable till " after forty hours of labour"; in a fourth, similarly hidden till after protracted labour. They therefore do not present the strict analogy to that forming the subject of this paper, which has been referred to, MIrs. W. having had several children, and there being no patency of the os whatever.

Burns continues: "It is also possible for the os uteri to be closed in consequence of inflammation, so that it has been necessary to make an urtificial opening." + This is the only mention of obliterated os uteri the result of inflammation, which, in my limited resources of reference, I have been able to meet with. In conjunction with it, I take the liberty of here repeating, from the passage in the Dictionnaire le Medecine quotel by Mr. Hatton, the only sentence to my purpose :"But it is also demonstrated by fucts of anatomical pathology, that the orifice becomes completely obliterated in consequence of inflammation of the mucous membrane which invests it." Mr. Hatton's case appears not to have been of this character at all, but similar to those previously cited; for although, in it, the constriction or contraction was so great that "no os uteri could be detected," there had bcen no disease of the womb, so far as ascertainable; and the impregnation indisputably implies some degree of patency, however minute. Then, it was a first pregnancy, and the patient had menstruated regularly from the age of sixteen (whether this regularity has regard to time, or quantity, or both, is not stated): and there was " a slight degree of puckering, or rather roughiness," concluded to be the site of the (assumed) imperforate os uteri.

The two extracts in the preceding paragraph, from Burns and the Dictionnaire de Médecine, are well illustrated by the casc renorted by me, some of the antecedents of which $I$ will now give. Mrs. W. had long been severcly aftlicted by a con. dition of the womb which, though its real character is still matter of dispute, is well understood by ulceration of the mouth and neck, accompanied by excessive discharge, much pain and exhaustion. She came under my care towards the close of 1855 , in a very broken-down condition; life seemed burdensome, and she was scarcely able to move about, having becn an invalid from the same cause, in greater or less severity, for some years before, during which she had not been pregnant, and had undergone medical treatment without relief. A few weeks attention, on the principles so ably laid down by Dr. Bennet, very much improved her state; and, by perseverance in the same course for a further period, she ccased to come to me, bcing quite restored to health, and in the enjoyment of comfort and strength, which she had long been deprived of. I heard no more of her till she called to engage me to attend at her confinement.

With reference to my inquiries at the bedside, alrealy referred to, as to any seusation of uneasiness in the uterine region after she became awnr quently drew from her the following facts :- That, in her fifth month, as she thought, she accompanied her husbaud on an excursion trip by railway to DIanchester; that, as is usual on such "pleasure" jaunts, the progress, what with stoppages and delays, was made as tedious as possible, causing her considerable uneasiness then and during her fatiguing wallis through the streets; that they left Manchester about 10 o'clock at night, and arrived again at Leeds between 4 and 5 next morning. This long confinement to a cramped position greatly increased the uneasiness in the luwer part of the body, so that she had much pair and diffieulty in reaching her home, which is about three quarters of a mile from the railway station. Her sufferings in this way continued till within six weeks of her delivery, when they altogether ceased; but she had not applied for help any where, under the idea that, though un. known in her past experience, they depended upon her pregnancy. I sulmit that there is here a satisfactory explanation of a case which, so far as I have been able to discover, is singular as to the perfect obliteration of the os, not only after impreguation, but after several natural full-timed births.

+ " Vide Case by Campardon, in Recusil Period. tom. xii, p. 22\%. Muscat gives a case where, in consenuence of injury by the furceps, the os uteri was so small that it would not admit a probe. $\lambda$ number of incisions were made round it, after which it dilated. In the next preguancy, slighter incisions sufnced; and in the last, none were reifuirel. dubertin perfurmed in case of this kind the Casarcan operation. In a subsequent precmancy, in the seventh month, the cicatrix was runtured, and by very little enlarremen a child was successtully extracted. In a case by ciautier, the os uteri was a child wis suceessfully extrneten. Th a case by cautier, ho os uteri was were retained, and required a perfuration for their evacuation." 